\title{
CYTOLOGICAL AND BACTERIOLOGICAL SAMPLING FROM FILTERS USED FOR EMBRYO RECOVERY TO EVALUATE THE UTERINE STATUS OF DONOR MARES
}

\author{
Carlos Carmelo PÉREZ-MARÍN ${ }^{1 *}$, Guillermo VIZUETE ${ }^{1}$, Carmen BORGE ${ }^{2}$ \\ and Juan Jose GALISTEO ${ }^{3}$
}

${ }^{1}$ Department of Animal Medicine and Surgery and ${ }^{2}$ Department of Animal Health, Faculty of Veterinary Medicine, University of Cordoba, 14014 Cordoba, Spain; ${ }^{3}$ Centro Militar de Cría Caballar de Ecija, Cría Caballar de las F.A.S., Ecija (Sevilla), Spain

(Received 11 April 2018; accepted 25 July 2018)

While testing for uterine bacterial infection is usually performed prior to artificial insemination (AI), samples taken during or after embryo flushing are generally not assessed either in subfertile and old mares or in fertile mares, even though knowledge of the status of the uterine environment in which the embryo is to develop would help to predict the outcome of embryo transfer programmes. The presence of bacteria and inflammatory cells in the liquid retained in the filter after uterine flushing in donors was determined at the moment of embryo recovery. Primarily, a group of mares $(\mathrm{n}=8)$ displaying evident clinical signs of endometritis was selected to evaluate the cytological and bacteriological findings in filters after uterine flushing and in uterine cotton swabs. Two uterine samples (for cytological and bacterial evaluation) were taken with cotton swabs and, subsequently, the uterus was flushed and the efflux was also subjected to bacteriological and cytological analysis. Later, a group of donors $(n=20)$ was also involved to evaluate the presence of bacteria and polymorphonuclear leukocytes (PMN). After embryo flushing and collection, the efflux retained in the filter was evaluated by cytology and bacteriology. A sterile cotton swab was then scrubbed on the filter mesh, and a bacterial culture was performed. The embryo recovery rate was $30 \%(\mathrm{n}=6)$; Escherichia coli was isolated in one efflux sample collected from embryo-productive flushings, while the other five samples were negative by culture. Bacterial growth (not considered as contamination) was observed in a total of three samples, although no inflammatory cells were detected. Bacteria were isolated in endometrial samples collected after embryo flushing in donor mares, although inflammatory cells were never present in the uterus of mares from which embryos were recovered. In the absence of clinical signs, cytological and/or bacteriological samplings are not very useful for estimating the success of embryo recovery in donor mares, but evaluation of the filter and efflux after uterine flushing in donors may provide valuable information regarding uterine status at embryo collection.

Key words: Embryo transfer, efflux, endometrium, cytology, bacteria, mare

*Corresponding author: E-mail: pv2pemac@uco.es; Phone: 0034 (957) 219-716; Mobile: 0034 (957) 211-093 
Endometrial cytology and culture are tools providing considerable information on the endometrial environment in mares (Riddle et al., 2007; Causey, 2010; Nielsen et al., 2010). The combination of these two techniques (cytology and culture) might serve as a guideline in the diagnosis and appropriate treatment of mares, by eliminating false positives and negatives (LeBlanc et al., 2007; Nielsen et al., 2010). While uterine cultures provide useful information for the diagnosis of uterine contamination, uterine cytology supplies direct evidence of uterine inflammation and helps to identify false positive cultures. Consequently, uterine culture will provide ambiguous or misleading results if uterine cytology is not performed (Riddle et al., 2007). Endometritis is the foremost signal of infertility in mares (LeBlanc, 2010). A range of diagnostic techniques has been reported, including clinical examination, transrectal ultrasonography and palpation assessment, endometrial culture, cytology, and biopsy (Riddle et al., 2007).

A number of authors have compared the efficacy of different techniques for assessing endometrial cytology in mares (Cocchia et al., 2012; Overbeck et al., 2013). Although the cotton-swab method is reportedly the fastest, the area in contact with the endometrium is reduced to only $1-2 \mathrm{~cm}^{2}$ (LeBlanc, 2010). This method may therefore not yield representative results for the diagnosis of subclinical endometritis and local endometrial infection. The biopsy method enables a more representative sample to be obtained, although it is also more traumatic. The cytobrush is as rapid as the cotton-swab technique, and the area in contact with the endometrium is slightly larger. The low-volume uterine flush method consists of uterine lavage by infusing $60-120 \mathrm{ml}$ of sterile solution, which is expanded throughout the endometrium by massage and then recovered for subsequent sample assessment. It requires more time than the methods described previously, but ensures that a more representative sample of the endometrial surface is obtained; however, some authors note that it may be more aggressive and more damaging to the uterine endothelium than other techniques (Brook, 1993).

Filters are generally discarded after embryo collection. However, both the filter and the efflux (fluid) retained in it might offer valuable information on the uterine environment, in terms of bacterial growth and the presence of inflammatory cells. Few studies have addressed the presence of bacteria and inflammatory cells in the uterus of embryo donor mares. Douglas et al. (1985) reported that subfertile mares often harbour pathogens, which are associated with the failure to recover embryos. In this study we tested the hypothesis that donor mares with positive cytology or bacteriology, or both together, have a reduced success in embryo recovery and quality, and that the flushing fluid could be a useful sample to carry out these analyses in donor mares. 
PÉREZ-MARÍN et al.

\section{Materials and methods}

Animals

This study involved a total of 28 non-lactating Hispano-Arabian mares, between 4 and 18 years of age, reared in Southern Spain (Ecija, Seville) in a Mediterranean climate. The mares were kept in paddocks and fed on alfalfa and grass hay, supplemented with concentrate, with free access to water and to tracemineralised salt. All mares showed a body condition score between 5.0 and 7.0 (using a 9-point scale).

In order to validate the procedures to be used for the isolation of bacteria and examination of inflammatory cells, mares displaying clinical endometritis (Group $1 ; \mathrm{n}=8$ ) were sampled during dioestrus, when a mature CL was observed. Endometritis was confirmed by the ultrasound presence of intraluminal uterine fluid.

Likewise, 20 donor mares (Group 2) were daily monitored by transrectal ultrasonography (ovaries and uterus) when signs of oestrus were detected. A linear-array scanner (Falco, Esaote, Barcelona, Spain) equipped with a $5.0 \mathrm{MHz}$, Bmode, transrectal transducer was used for this purpose. Also, endometrial culture was carried out at the beginning of oestrus using cotton swabs, and negative bacteriological and fungal growth was observed. When ovulation was imminent (i.e. follicular diameter approximately $40 \mathrm{~mm}$, loss of follicle spherical shape, and uterine oedema), mares were inseminated with fresh semen from tested stallions; artificial insemination was repeated at 48-h intervals until ovulation was detected.

\section{Uterine flushing}

Uterine flushing was performed on day 6.5 after ovulation in both groups because embryos obtained from donor mares were vitrified. Animals were ultrasonographically monitored to evaluate the ovary (presence of corpus luteum) and uterus. For uterine flushing, mares were sedated with $20 \mu \mathrm{g} / \mathrm{kg}$ detomidine hydrochloride (Domosedan, Pfizer, Spain) and the vulva and perineum were then cleaned with povidone iodine. A Foley-type balloon-tipped catheter (Bioniche Animal Health, Pullman, USA) was lubricated with sterile, non-spermicidal gel, its tip was placed at the uterine lumen close to the cervix and the balloon was inflated with air. The uterus was flushed four times, using 1 litre of Ringer-lactate media at $37.5{ }^{\circ} \mathrm{C}$ each time, and the recovered fluid was filtered through an sterile in-line filter, pore size $73 \mu \mathrm{m}$ (Miniflush, Minitube Iberica, Tarragona, Spain). Then the filter was opened in a laminar flow cabinet; in Group 2, the embryo was searched under a stereoscopic microscopy (Nikon SMZ645, Japan). The filter content was transferred to sterile 50-ml conical tubes, and bacteriological and cytological analyses were carried out. 
Efflux clarity was recorded in all mares after uterine flushing, being graded as clear (0), and either partially (1) or highly (2) cellular, depending on the amount of cells, mucus, debris or other matter contained in the efflux.

\section{Sample collection for bacterial and cytological analysis}

A double-guarded uterine swab (Minitube Iberica, Tarragona, Spain) was used to obtain cytological and microbiological samples in Group $1(n=8)$. It was guided manually through the vulva, vagina and cervix to reach the uterus. Once positioned in the uterine body, the swab was rolled on the endometrial surface. It was then retracted and removed, and rolled gently on a sterile glass slide which was then dipped in Romanowski stain (fixative, eosin and blue solutions for fast staining; Panreac, Barcelona, Spain).

After uterine flushing (in both groups), the efflux retained in the filter was collected in sterile $50-\mathrm{ml}$ conical tubes and centrifuged at $300 \mathrm{~g}$ for $10 \mathrm{~min}$. The supernatant was removed and the remaining pellet was resuspended in a small amount of supernatant lavage fluid, streaked onto a glass slide, and allowed to air-dry before being dipped in Romanowski stain (Panreac, Barcelona, Spain); the slide was then examined by light microscopy $(\times 400$ and $\times 1000$ magnification). Two slides were prepared per flush, and 200 cells were counted per slide. Donor-mare samples obtained from the filter mesh (rolling a cotton swab on the mesh surface) and efflux retained in the filter after centrifugation were compared; no uterine swab was used in donor mares.

Cytology slides were examined by an experienced technician, who evaluated epithelial cells, neutrophils and other inflammatory cells. The proportion of PMNs as a percentage of total cells was used to classify the uterus as $0(<0.5 \%)$, $1(0.5-5 \%), 2(>5-30 \%)$ and $3(>30 \%)$ (Cocchia et al., 2012), acute endometritis being diagnosed when the $\%$ of PMN was $>0.5 \%$.

Uterine bacterial cultures were plated on different media (Blood agar, Mannitol agar, MacConkey agar, XLD agar, and Sabouraud Dextrose Agar) within $3 \mathrm{~h}$ of sample collection. After 24-h incubation in atmospheric air at $37^{\circ} \mathrm{C}$, the plates were examined for growth, and were re-examined at $48 \mathrm{~h}$ and $72 \mathrm{~h}$ for the presence of bacteria or yeasts. Microorganisms were identified by conventional methods using API $^{\circledR}$ strips (API 20E ${ }^{\circledR}$, API 20Strep ${ }^{\circledR}$, API Staph ${ }^{\circledR}$, APICoryne ${ }^{\circledR}$; BioMérieux, Spain). Growth was classified as abundant (>100 CFU/ plate), moderate (21-100 CFU/plate), sparse (1-20 CFU/plate), or insignificant (0 CFU/plate), as recommended by Ball et al. (1988). The bacteriological classification was no growth, mixed flora, or single isolate. According to Ball et al. (1988), microbiologic cultures were considered positive for pathogenic microorganisms if more than 20 colonies of Candida spp., Trueperella spp., $\beta$-haemolytic streptococci, coagulase-positive staphylococci, Escherichia coli, Pseudomonas aeruginosa or Klebsiella pneumoniae were observed per plate. 


\section{Statistical analysis}

Comparisons were made of cytological results, culture results, isolated microorganisms, clinical signs of endometritis, and embryo recovery rates. Categorical variables were compared using contingency tables and the Pearson chisquare test. Differences were considered statistically significant at $\mathrm{P} \leq 0.05$. The SPSS 15.0 package (SPSS, Chicago, IL, USA) was used for statistical analysis.

In Group 1, endometritis signs and cytological and bacteriological assessment in the efflux retained in the filter were related to the cotton swab. In Group 2, i.e. donor mares, the presence of embryo and bacteriological and cytological evaluation was analysed in the efflux retained in the filter.

Sensitivity and specificity of the different diagnostic tests were calculated. The sensitivity of the diagnostic tests used was calculated as the proportion of mares with positive diagnoses of endometritis (based on positive culture and/or cytology) of all mares in which an embryo was not obtained. Specificity was calculated as the proportion of mares without PMNs and/or negative bacterial cultures of all mares from which an embryo was recovered. Negative predictive value was calculated as the mares correctly considered negative (negative cytology and/or culture in mares in which an embryo was recovered) between all mares diagnosed as negative. Positive predictive value was calculated as the mares correctly considered positive for endometritis (i.e., positive cytology and/or culture in mares in which an embryo was not obtained) of all mares diagnosed as positive for endometritis. The positive embryo recovery was regarded as the best standard.

\section{Results}

Validation of procedures for the isolation of bacteria and examination of inflammatory cells in mares with evident endometritis

The results of the cytological evaluation of the residual filter flush in mares displaying clinical endometritis (Group 1) were similar to those obtained using the conventional cotton-swab method (Table 1).

The ability of these two methods to determine the extent of bacteriological growth was compared. In five mares (62.5\%), the two methods yielded similar numbers of colony-forming units (CFU). In two mares, $\mathrm{CFU}$ numbers were higher in the efflux samples, while in the other one, numbers were higher in the cottonswab sample. When bacteria were isolated and identified, six mares (75\%) showed similar results by both methods, while one displayed negative bacterial growth in the cotton-swab sample but positive growth in the efflux sample. In the other mare, a discrepancy was observed between sampling methods with regard to bacterial identification: while the cotton-swab culture was positive for Streptococcus equi subsp. zooepidemicus and Staphylococcus aureus, the efflux culture was positive for Streptococcus equi subsp. zooepidemicus, E. coli and Enterococcus. 
Table 1

Cytological and bacteriological findings in mares displaying evident endometritis (Group 1)

\begin{tabular}{lcclcc}
\hline \multirow{2}{*}{ Mares } & \multicolumn{2}{c}{ Presence of PMNs (\%) } & & \multicolumn{2}{c}{ Bacterial growth } \\
\cline { 2 - 3 } \cline { 5 - 6 } & Residual filter flush & Cotton swab & & Residual filter flush & Cotton swab \\
\hline 1 & $3(60)$ & $3(69)$ & & $\mathrm{D}$ & $\mathrm{D}$ \\
2 & $1(1)$ & $1(3)$ & & $\mathrm{D}$ & $\mathrm{D}$ \\
3 & $0(0)$ & $0(0)$ & & $\mathrm{C}$ & $\mathrm{D}$ \\
4 & $3(85)$ & $3(75)$ & & $\mathrm{B}$ & $\mathrm{D}$ \\
5 & $0(0)$ & $0(0)$ & & $\mathrm{C}$ & $\mathrm{C}$ \\
6 & $3(98)$ & $3(92)$ & & $\mathrm{D}$ & $\mathrm{D}$ \\
7 & $1(2)$ & $1(3)$ & & $\mathrm{C}$ & $\mathrm{A}$ \\
8 & $3(89)$ & $3(41)$ & & $\mathrm{B}$ & $\mathrm{B}$ \\
\hline
\end{tabular}

PMNs = polymorphonuclear leukocytes; Presence of PMNs: $0(<0.5 \%), 1(0.5-5 \%), 2(5-30 \%)$ and $3(>30 \%) ; \mathrm{A}=$ insignificant, $0 \mathrm{CFU} /$ plate; $\mathrm{B}=$ sparse, $1-20 \mathrm{CFU} /$ plate; $\mathrm{C}=$ moderate, $21-$ $100 \mathrm{CFU} /$ plate; $\mathrm{D}=$ abundant, $>100 \mathrm{CFU}$ (colony forming units)/plate

A preliminary comparison was also carried out in Group 1 to analyse potential differences between bacterial cultures from the filter sample and the efflux sample, both obtained during uterine flushing. In four mares (50\%), CFU numbers were similar for the two methods; in three, numbers were higher in the efflux than in the filter samples, while in the eighth the reverse was true.

All efflux samples collected in Group 1 were highly turbid and dirty. From two cultures only Streptococcus equi subsp. zooepidemicus was isolated, while in the rest a mixed culture was observed: one comprised two bacteria $(E$. coli and Enterococcus), three contained three bacteria (Streptococcus equi subsp. zooepidemicus, E. coli and Enterococcus) and two displayed four bacteria (Streptococcus equi subsp. zooepidemicus, E. coli, Klebsiella pneumonia and Streptococcus dysgalactiae in one case, and Streptococcus equi subsp. zooepidemicus, E. coli, Enterococcus and Staphylococcus aureus in the other). Analysis of the isolated bacteria showed that Streptococcus equi subsp. zooepidemicus was present in $7 / 8$ mares (87.5\%), E. coli in 6/8 (75\%), Enterococcus in 4/8 (50\%), and Staphylococcus aureus, Streptococcus dysgactiae and Klebsiella pneumonia in 1/8 (12.5\%).

\section{Endometrial bacteriological and cytological findings in donor mares}

A total of 20 embryo-flushing attempts were carried out, and 6 embryos were recovered (Group 2; Table 2). Inflammatory cells were identified in endometrial cytology samples for only three donor mares. One showed inflammation with $8.0 \%$ of PMNs/total cells, and the others had between 0.5 and $5 \%$ of PMNs/total cells. None of the mares with inflammatory cells displayed positive bacterial growth cultures, and no embryos were collected. 
Table 2

Cytological and bacteriological findings in efflux collected into the filter after uterine flushing and embryo recovery results in donor mares (Group 2)

\begin{tabular}{|c|c|c|c|c|c|}
\hline \multirow{2}{*}{$\begin{array}{l}\begin{array}{l}\text { Group 2 } \\
\text { (mares) }\end{array} \\
1\end{array}$} & \multirow{2}{*}{$\begin{array}{c}\begin{array}{c}\text { Efflux } \\
\text { clarity }\end{array} \\
3\end{array}$} & \multicolumn{2}{|c|}{$\begin{array}{l}\text { Bacterial growth } \\
\text { Residual filter flush }\end{array}$} & \multirow{2}{*}{$\begin{array}{c}\text { Presence of PMNs (\%) } \\
\text { Residual filter flush } \\
0\end{array}$} & \multirow{2}{*}{$\begin{array}{c}\text { Embryo } \\
\text { recovery } \\
-\end{array}$} \\
\hline & & $\mathrm{B}$ & Staph, Strep ${ }^{I}$ & & \\
\hline 2 & 1 & $\mathrm{~B}$ & E. coli & 0 & - \\
\hline 3 & 2 & $\mathrm{~B}$ & Strep ${ }^{I}$ & 0 & + \\
\hline 4 & 0 & A & & $1(0.5)$ & - \\
\hline 5 & 0 & A & & 0 & - \\
\hline 6 & 0 & $\mathrm{~A}$ & & 0 & + \\
\hline 7 & 0 & $\mathrm{~A}$ & & $1(0.5)$ & - \\
\hline 8 & 0 & A & & $2(8)$ & - \\
\hline 9 & 3 & $\mathrm{~B}$ & E. coli & 0 & + \\
\hline 10 & 2 & $\mathrm{~B}$ & Staph & 0 & - \\
\hline 11 & 1 & $\mathrm{C}$ & Strep ${ }^{2}$, Truep, E. coli & 0 & - \\
\hline 12 & 2 & $\mathrm{C}$ & Staph, Truep & 0 & - \\
\hline 13 & 0 & A & & 0 & - \\
\hline 14 & 0 & $\mathrm{~A}$ & & 0 & + \\
\hline 15 & 3 & $\mathrm{~B}$ & E. coli, Kleb & 0 & - \\
\hline 16 & 1 & $\mathrm{~B}$ & Truep & 0 & + \\
\hline 17 & 1 & $\mathrm{C}$ & E. coli & 0 & + \\
\hline 18 & 0 & $\mathrm{~A}$ & & 0 & - \\
\hline 19 & 2 & $\mathrm{~B}$ & non-identified & 0 & - \\
\hline 20 & 2 & $\mathrm{~B}$ & Strep ${ }^{I}$ & 0 & - \\
\hline
\end{tabular}

Bacterial growth: $\mathrm{A}=$ insignificant, $0 \mathrm{CFU} /$ plate; $\mathrm{B}=$ sparse, $1-20 \mathrm{CFU} /$ plate; $\mathrm{C}=$ moderate, $21-$ $100 \mathrm{CFU} /$ plate; $\mathrm{D}=$ abundant, $>100 \mathrm{CFU}$ (colony forming units)/plate; PMNs = polymorphonuclear leukocytes; Presence of PMNs: $0(<0.5 \%), 1(0.5-5 \%), 2(5-30 \%)$ and $3(>30 \%)$; Staph $=$ Staphylococcus aureus; Strep $^{l}=$ Streptococcus equi subsp. zooepidermicus; Strep $^{2}=$ Streptococcus dysgalactiae; Truep $=$ Trueperella spp $;$ Kleb $=$ Klebsiella pneumonia

Embryo-producing mares did not display positive cytology, i.e. no PMNs were observed in their efflux samples. Only one mare showed moderate growth of $E$. coli, which was considered as pathological growth, while the other isolates were considered as contamination (one with sparse growth of $E$. coli, one with sparse growth of Streptococcus equi subsp. zooepidemicus, and other with sparse growth of Trueperella spp.) (Table 2).

Different bacteria were isolated in a total of 12 uterine flushes, i.e. in $60 \%$ of the donors. In 8 of these cases, a single microorganism was isolated: E. coli on 3 plates, Streptococcus equi subsp. zooepidemicus on 2 plates, and Staphylococcus aureus and Trueperella spp. on one plate each; in all other cases, the microorganism could not be identified. In these samples, bacterial growth was mostly sparse $(<20 \mathrm{CFU})$, except for one plate on which moderate growth of $E$. coli (20-100 CFU) was observed. It should be clarified that only this last one was regarded as pathological bacterial growth, while the others were registered as con- 
tamination. The other four samples yielded mixed cultures. Concomitant growth of two different bacteria was observed in three cases: one with sparse growth of Streptococcus equi subsp. zooepidemicus and Staphylococcus aureus, another also with a sparse growth of E. coli and Klebsiella pneumoniae, and the third with moderate growth of Staphylococcus aureus and Trueperella spp. Finally, moderate growth of three different bacteria (Streptococcus dysgalactiae, Trueperella spp. and E. coli) was identified in one case. As mentioned before, only three cultures were regarded as pathologic microorganisms, because the CFUs were higher than 20 .

The efflux contained in the filter was clear and transparent in mares with negative bacterial cultures, but displayed varying degrees of turbidity in mares with positive cultures (Table 2).

The sensitivity of cytology and/or bacteriology in efflux samples from donor mares to detect endometritis (using embryo recovery as gold standard) ranged from 0.14 to 0.36 , while specificity was higher, ranging from 0.83 to 1.0 . The positive predictive value was also higher (ranging from 0.67 to 1.0 ) and the negative predictive value was reduced (ranging from 0.29 to 0.36 ) (Table 3 ).

\section{Table 3}

Sensitivity, specificity, negative and positive predictive value of cytology ( $\geq 0.5 \%$ PMNs), bacteriology ( $>20 \mathrm{CFU} /$ plate) or a combination of both in efflux samples for the diagnosis of endometritis in donor mares $(n=20)$ using the embryo recovery as the gold standard

\begin{tabular}{lccc}
\hline & Cytology & $\begin{array}{c}\text { Bacterial } \\
\text { culture }\end{array}$ & $\begin{array}{c}\text { Both } \\
\text { techniques }\end{array}$ \\
\hline Sensitivity & 0.21 & 0.14 & 0.36 \\
Specificity & 1.00 & 0.83 & 0.83 \\
Negative predictive value & 0.35 & 0.29 & 0.36 \\
Positive predictive value & 1.00 & 0.67 & 0.83 \\
\hline
\end{tabular}

PMNs = polymorphonuclear leukocytes; $\mathrm{CFU}=$ colony-forming units

\section{Discussion}

The maintenance of a sterile environment in the uterus of donor mares may be essential for improving the results of embryo transfer programmes. It has been suggested that the periovulatory uterine environment significantly affects pregnancy rates (Douglas et al., 1985), and it would be extremely useful to ascertain exactly how the presence of microorganisms, cellular response, histological architecture or hormonal environment in the uterus might affect reproductive performance in mares. However, little research has dealt with the uterine environment during embryo recovery. The equine embryo leaves the oviduct and enters the uterus around day 6 after ovulation. The uterus should offer the best pos- 
sible accommodation for the embryo, which, in transfer programmes, will remain there awaiting collection until days 6-7 after ovulation. However, the sampling techniques recommended for assessing endometrial status in mares cannot be used in donors because of the risk of embryo loss. The aim of this study was to determine the efficacy of sampling uterine efflux obtained during the flushing procedure as a means of assessing endometrial status, and to evaluate uterine bacteriological and cytological status in donor mares at the moment of embryo collection.

Routine non-invasive sampling methods for evaluating endometrial cytology status in mares include the cytobrush, cotton-swab and low-volume flush techniques, and bacteriological status can be also determined in the specimens thus obtained (LeBlanc et al., 2007; Davies Morel et al., 2013). Using the liquid obtained during embryo flushing, Koblischke et al. (2008) described that few donor mares $(14.9 \%)$ had positive bacteriological culture, although the authors did not describe either the cytological findings or the method used for isolating samples. The present study aimed to examine whether a new technique based on the analysis of efflux retained in the filter after embryo collection could constitute a sensitive and specific method for obtaining reliable information on uterine status in donors. Firstly, mares diagnosed as endometritis-positive by uterine ultrasonography, bacteriology and cytology were used to compare the different sampling methods. Cytological testing of specimens obtained by cotton swabs yielded results similar to those obtained in efflux samples. Isolation and identification of microorganisms were then carried out on filter-mesh samples and on efflux retained in the filter after embryo recovery, using the cotton-swab procedure. Again, similar results were obtained, confirming that these sampling techniques were equally effective. These findings were crucial to the subsequent decision to use efflux sampling in donor mares with a view to evaluating uterine cell content.

In order to test the hypothesis that no microorganisms would be present in the uterus of donor mares at embryo recovery, a new method was used involving sampling of the efflux retained in the embryo filter after flushing, with a view to reducing potential embryo loss. Earlier testing of mares displaying clinical signs of endometritis indicated that efflux cultures yielded results similar to those obtained using the cotton-swab method. Bacteria were isolated in samples obtained from donors, including embryo-producing mares. The combined findings of bacteriological isolation and endometrial cytology indicated that no donor mares were positive for both bacteria and endometritis, which might be indicative of a non-active infection or inflammation.

LeBlanc et al. (2007) have reported that the low-volume uterine flush method is a fast, accurate and practical way of diagnosing endometritis in chronically infertile mares, with a sensitivity and specificity approaching 0.75 and 0.9 , respectively. The efflux method tested here is quite similar to the low-volume flush technique, but by allowing the use of efflux retained in the filter, it avoids 
compromising potential embryo collection. The results indicate that this sampling method offers a low degree of sensitivity for cytological assessment and bacterial isolation ( 0.21 and 0.14 , respectively), but a high specificity ( 1.00 and 0.83 , respectively). It has been suggested that fewer pathogenic microorganisms may be detected by the cotton-swab technique than by low-volume flush because the latter method samples a larger surface area (Leblanc et al., 2007), as occurs when efflux testing after uterine flushing at embryo transfer is carried out.

Although biopsy cannot always be used for sampling, the presence of neutrophils in a tissue specimen is considered the 'best standard' for diagnosing endometritis (Nielsen, 2005). In the present study, endometrial inflammatory cells were detected in only three donor mares (obtained from the efflux or filter), none of which displayed bacterial growth. The absence of neutrophils points to a possible non-reactive infection by the bacteria isolated. Riddle et al. (2007) have reported that Streptococcus equi subsp. zooepidemicus, E. coli, Staphylococcus, Micrococcus, Bacillus and haemolytic streptococci are saprophyte species in the equine uterus and may not promote reactive infection. Most bacteria isolated here in donor mares $(75 \%)$ belonged to these species and appeared as single or mixed growth. Other authors (LeBlanc et al., 2007) found no correlation between the positive bacterial cultures obtained from low-volume flush samples and the degree of inflammation, since no PMNs were observed. It has also been reported that the presence of PMNs in endometrial samples depends on the type of bacteria isolated; detection of PMNs in the uterus is more frequently associated with $\beta$-haemolytic streptococci than with E. coli (Nielsen et al., 2010). The type of microorganisms recovered by cotton-swab sampling may also influence cytology test results (Nielsen et al., 2010). A number of authors suggest that the type of inflammatory cells present within the endometrium is affected by the phase of the oestrous cycle. Moreover, variations in cytological patterns presumably reflect changing hormone levels, and neutrophil migration into the uterine lumen during the period of progesterone dominance is lower than during maximal oestrogen dominance (Ball et al., 1988; LeBlanc et al., 2007; Riddle et al., 2007). In the present study, no uterine inflammatory cells were detected in $85 \%(17 / 20)$ of donor mares at embryo recovery on day 6.5 after ovulation, i.e. during the period of progesterone dominance.

It has been reported that the isolation of endometrial microorganisms at mating is always associated with a decrease in the pregnancy rate, regardless of the cytological findings (Riddle et al., 2007). In a recent study of endometrial cytology it was observed that a threshold value of $\geq 1 \%$ PMNs was linked to reduced live foaling rates (Davies Morel et al., 2013). The results obtained here indicate that bacterial isolation does not impede embryo recovery since one donor mare, in which embryos were recovered, displayed pathological bacterial growth in the uterus; however, this situation is not usual. In the present study (in which embryo recovery was used as the gold standard), cytology offered better sensitiv- 
ity and specificity in donor mares than reported by others using live foaling as the gold standard (Davies Morel et al., 2013); in contrast, true negatives were lower when bacteriology or both cytology and bacterial cultures were used. Studies show that cytology and bacteriology have higher sensitivity and specificity to determine endometritis when biopsy is the gold standard (Nielsen, 2005; Leblanc et al., 2007) than when clinical outcomes (as live foal) (Davies Morel et al., 2013) or embryo recovery (as described in the present study) are used. According to the results, it can be expected that the probability to recover embryos in donor mares will be compromised when endometritis is diagnosed (i.e., positive cytology and/or positive bacterial growth), as is derived from the positive predictive value obtained (from 0.67 to 1.00 ). Embryo recovery is associated with many other factors, and then negative endometritis diagnosis in donors does not guarantee a successful embryo collection.

The appearance of the efflux collected in the group of mares with evident endometritis differed considerably from that obtained during embryo transfer in the donor group, bacterial growth being associated with dirtier efflux. Leblanc et al. (2007) also report that a cloudy, mucoid efflux collected from mares with endometritis is associated with the isolation of microorganisms. Here, isolation of Staphylococcus was always linked with a cloudy efflux, whilst findings for other bacteria varied. In view of the results obtained here, and as reported by others (Leblanc et al., 2007), the culture of liquid collected from filter (as occurs during the embryo transfer procedure) may be considered as not contaminated - even though bacteria are isolated - when it is accompanied by clear efflux, no changes in $\mathrm{pH}$, non-inflammatory or hypocellular cytology, and absence of neutrophils in the endometrial tissue obtained by biopsy.

The embryo recovery rate $(30 \%)$ was lower than reported by other authors (Jacob et al., 2012). This may be due in part to the difficulty in selecting suitable donors, since the Hispano-Arabian horse is an endangered breed and donor availability is limited. It should also be noted that embryos were collected on day 6.5 , since this study was conducted in conjunction with an embryo cryopreservation programme; earlier embryo collection appears to be associated with lower embryo recovery rates (Jacob et al., 2012). Finally, embryo recovery was carried out from October to February, i.e. during the transitional breeding season in Spain. It has been reported that the embryo recovery rate is lower during the nonbreeding season ( $25 \%$ between September and February, as against $80 \%$ between March and September) (Koblischke et al., 2008); this assertion is borne out by the findings of the present study, in which embryo recovery rates during the breeding season rose to $45.3 \%$ (unpublished data).

In conclusion, analysis of the efflux retained in the filter after embryo collection in mares could be an efficient method to evaluate the cytological and bacteriological status of the uterus of donor mares, although failures for embryo recovery in donors are not tightly linked with the presence of endometritis. 


\section{Acknowledgement}

This study was supported by INIA-FEDER RZ2008-00025-00-00.

\section{References}

Ball, B. A., Shin, S. J., Patten, V. H., Lein, D. H. and Woods, G. L. (1988): Use of a low-volume uterine flush for microbiologic and cytologic examination of the mare's endometrium. Theriogenology 29, 1269-1283.

Brook, D. (1993): Uterine cytology. In: McKinnon, A. O. and Voss, J. L. (eds) Equine Reproduction. Lea and Febiger, London. pp. 246-254.

Causey, R. C. (2010): Making sense of equine uterine infections: the many faces of physical clearance. Vet. J. 172, 405-421.

Cocchia, N., Paciello, O., Auletta, L., Uccello, V., Silvestro, L., Mallardo, K., Paraggio, G. and Pasolini, M. P. (2012): Comparison of the cytobrush, cottonswab, and low-volume uterine flush techniques to evaluate endometrial cytology for diagnosing endometritis in chronically infertile mares. Theriogenology 77, 89-98.

Davies Morel, M. C. G., Lawlor, O. and Nash, D. M. (2013): Equine endometrial cytology and bacteriology: Effectiveness for predicting live foaling rates. Vet. J. 198, 206-211.

Douglas, R. H., Burns, P. J. and Hershman, L. (1985): Physiological and commercial parameters for producing progeny from subfertile mares by embryo transfer. Equine Vet. J. (Suppl.) 3, 111-114.

Jacob, J. C. F., Haag, K. T., Santos, G. O., Oliveira, J. P., Gastal, M. O. and Gastal, E. L. (2012): Effect of embryo age and recipient asynchrony on pregnancy rates in a commercial equine embryo transfer program. Theriogenology 77, 1159-1166.

Koblischke, P., Kindahl, H., Budik, S., Aurich, J., Palm, F., Walter, I., Kolodziejek, J., Nowotny, N., Hoppen, H. O. and Aurich, C. (2008): Embryo transfer induces a subclinical endometritis in recipient mares which can be prevented by treatment with non-steroid antiinflammatory drugs. Theriogenology 70, 1147-1158.

LeBlanc, M. M. (2010): Advances in the diagnosis and treatment of chronic infectious and postmating-induced endometritis in the mare. Reprod. Domest. Anim. 45, 21-27.

LeBlanc, M. M., Magsig, J. and Stromberg, A. J. (2007): Use of a low-volume uterine flush for diagnosing endometritis in chronically infertile mares. Theriogenology 68, 403-412.

Nielsen, J. M. (2005): Endometritis in the mare: A diagnostic study comparing cultures from swab and biopsy. Theriogenology 64, 510-518.

Nielsen, J. M., Troedsson, M. H., Pedersen, M. R., Bojesen, A. M., Lehn-Jensen, H. and Zent, W. W. (2010): Diagnosis of endometritis in the mare based on bacteriological and cytological examinations of the endometrium: comparison of results obtained by swabs and biopsies. J. Equine Vet. Sci. 30, 27-30.

Overbeck, W., Jäger, K., Schoon, H. A. and Witte, T. S. (2013): Comparison of cytological and histological examinations in different locations of the equine uterus - an in vitro study. Theriogenology 79, 1262-1268.

Riddle, W. T., LeBlanc, M. M. and Stromberg, A. J. (2007): Relationships between uterine culture, cytology and pregnancy rates in a Thoroughbred practice. Theriogenology 68, 395-402. 